\title{
NUMERICAL ANALYSIS OF MATERIAL AND MANUFACTURING FACTORS IN RIVETED JOINTS UNDER THE IMPERJA PROJECT
}

\author{
Szymczyk Elżbieta \\ Bogusz Pawel \\ Sławiński Grzegorz \\ Jachimowicz Jerzy \\ Military University of Technology, Warsaw, Poland
}

\section{INTRODUCTION}

The aim of the project was to improve fatigue performance of riveted joints in airframes. Fatigue strength of a joint depends on structural, material and manufacturing factors. The project involved numerical and experimental analysis of material factors and manufacturing imperfections.

The paper deals with the analysis of material structure and properties by means of the optical and SE methods. Static monotonic tests for sheet and rivet materials were carried out. ARAMIS optical system was used for the study of deformation and strain fields in the material during loading. This tool offers the possibility of a non-contact measurement with 3D image correlation methods (digital image correlation, DIC) using high-resolution digital CCD cameras.

In ductile materials (such as aluminium alloy), subjected to appropriate loading conditions, voids may form, which grow and coalesce leading to crack formation and potential failure. A micro crack may be initiated at the inclusion particles and then voids grow around it. Experimental studies showed that these processes are strongly influenced by hydrostatic stress (Gurson's material model). SEM analysis of material structure was carried out after performing static tests.

In the paper, the authors present the influence of a material model on the results of numerical simulation of the tensile loaded samples with open and riveted holes. The application of Gurson's material model allows observation of crack growth in the sample cross-section and determination of the sheet rupture as the moment when constraint force decreases to zero (material separation occurs).

\section{EXPERIMENTAL INVESTIGATION}

\subsection{Description of the specimens and measurement methods}

The objective of the investigation was to evaluate the material properties of 2024T3 aluminium alloy subjected to various treatments. The following rectangular cross-section specimens were prepared:

- $\quad$ bare/non cladded axially rolled specimens (marked BPw\#);

- bare/non cladded crosswise rolled specimens (marked BPp\#);

- cladded axially rolled specimens (marked ZPw\#);

- cladded crosswise rolled specimens (marked ZPp\#).

The specimens were statically stretched at a constant loading rate. An electro-resistant method based on strain gauges and the non-contact optical 3D system Aramis were applied to measure axial/longitudinal and transversal strains of the specimens. Based on the data obtained from those tests, tensile curves and material constants were evaluated. 


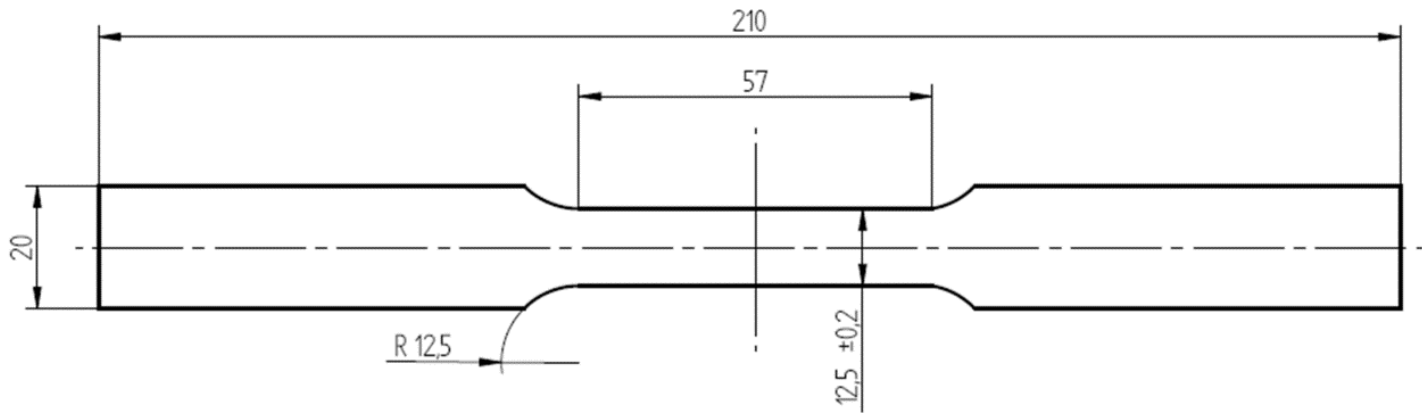

Fig. 1. Scheme and overall dimensions of the specimen [ASTM A 370-03a]

Four specimens were tested for each type of treatment. The scheme and overall dimensions of the specimen are presented in Figure 1. Strain gauges were used only in selected specimens (two of each type), marked with the letter T. A detailed description of the specimens is presented in Table 1.

The Vishay EA-06-060RZ-120/E strain gauge rosettes with resistance of $120 \Omega$ and a gauge factor of 2,07 were installed in the centre of the measurement area of the specimens. A rectangular strain rosette was placed on each specimen so that the central strain gauge was directed axially and the other two were deployed symmetrically at an angle of $\pm 45^{\circ}$ (Fig. 2).

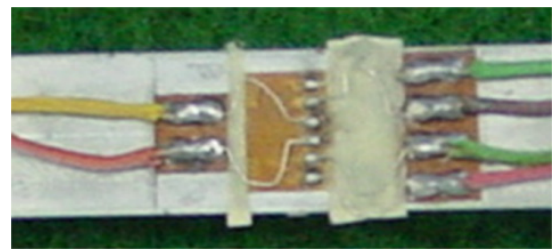

Fig. 2. Arrangement of a strain gauge rosette on the specimen

Table 1. Description and detailed dimensions/thickness of selected specimens

\begin{tabular}{|c|c|c|c|c|c|c|}
\hline \multirow{2}{*}{ No.. } & \multirow{2}{*}{$\begin{array}{l}\text { Specimen } \\
\text { marking }\end{array}$} & \multirow{2}{*}{ Description } & Thickness & Width & \multirow{2}{*}{$\begin{array}{l}\text { Strain gauge } \\
\text { usage }\end{array}$} & \multirow{2}{*}{$\begin{array}{l}\text { Aramis } \\
\text { optical system }\end{array}$} \\
\hline & & & {$[\mathrm{mm}]$} & {$[\mathrm{mm}]$} & & \\
\hline 1 & BPw2 & \multirow{3}{*}{$\begin{array}{l}\text { bare, } \\
\text { rolled } \\
\text { axially }\end{array}$} & 1,21 & 12,5 & No & Applied \\
\hline 2 & BPw1T & & 1,21 & 12,5 & $\begin{array}{l}\text { Strain gauge } \\
\text { rosette }\end{array}$ & - \\
\hline 3 & BPw2T & & 1,21 & 12,5 & $\begin{array}{l}\text { Strain gauge } \\
\text { rosette }\end{array}$ & - \\
\hline 4 & BPp1T & \multirow{2}{*}{$\begin{array}{l}\text { bare, } \\
\text { rolled } \\
\text { crosswise }\end{array}$} & 1,21 & 12,5 & $\begin{array}{l}\text { Strain gauge } \\
\text { rosette }\end{array}$ & Applied \\
\hline 5 & BPp2T & & 1,21 & 12,5 & $\begin{array}{l}\text { Strain gauge } \\
\text { rosette }\end{array}$ & - \\
\hline 6 & ZPw1T & \multirow{2}{*}{$\begin{array}{l}\text { cladded*, } \\
\text { rolled } \\
\text { axially }\end{array}$} & 1,20 & 12,5 & $\begin{array}{l}\text { Strain gauge } \\
\text { rosette }\end{array}$ & - \\
\hline 7 & ZPw2T & & 1,20 & 12,5 & $\begin{array}{l}\text { Strain gauge } \\
\text { rosette }\end{array}$ & Applied \\
\hline 8 & ZPp1 & \multirow{3}{*}{$\begin{array}{l}\text { cladded }{ }^{*}, \\
\text { rolled } \\
\text { crosswise }\end{array}$} & 1,20 & 12,5 & No & Applied \\
\hline 9 & ZPp1T & & 1,20 & 12,5 & $\begin{array}{l}\text { Strain gauge } \\
\text { rosette }\end{array}$ & - \\
\hline 10 & ZPp2T & & 1,20 & 12,5 & $\begin{array}{l}\text { Strain gauge } \\
\text { rosette }\end{array}$ & - \\
\hline
\end{tabular}

Clad thickness $60 \mu \mathrm{m}$. 
One surface of each specimen (the one without strain gauges) was prepared for non-contact optical deformation measurements with the Aramis system. The preparation of the specimen required the surface to be coloured with white paint characterised by good adhesion and great elasticity (to measure large strains in the neck area). Subsequently, a part of the specimen was sprayed with a random pattern of black spots with a proper diameter. The facture of the painted surface of the specimen is presented in Fig. 3.

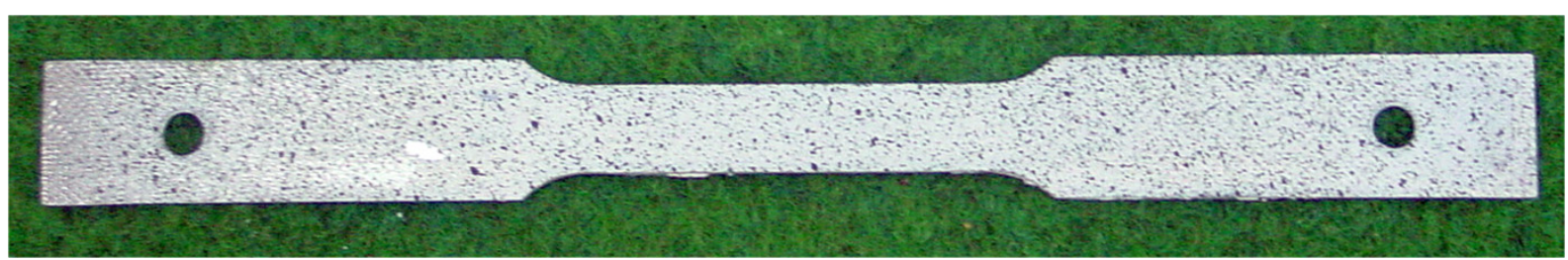

Fig. 3. The surface preparation of the specimens for non-contact optical deformation measurements

Static tension tests were performed on the hydraulic tension machine Instron 8802 presented in Fig. 4. The specimens were stretched at a constant loading rate equal to $12 \mathrm{~mm} / \mathrm{min}$. The displacement of the moving head and load were recorded with a sampling frequency of $20 \mathrm{~Hz}$.

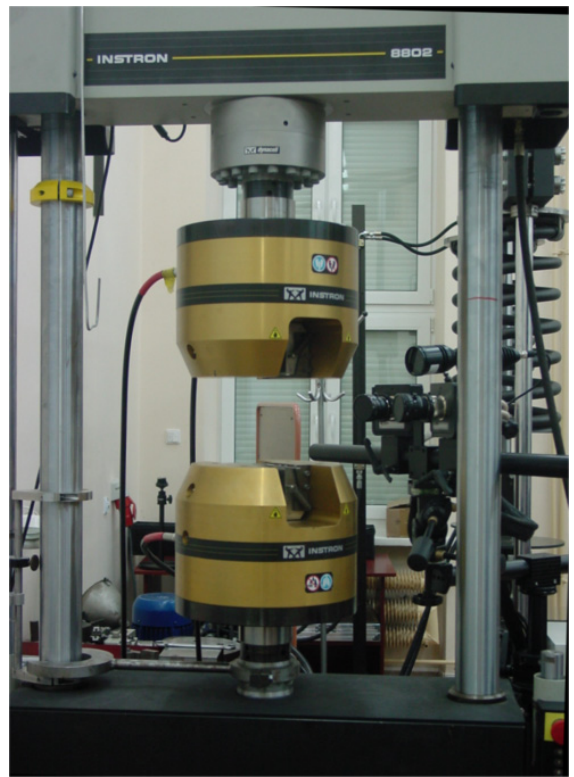

Fig. 4. Hydraulic tension machine Intron 8802

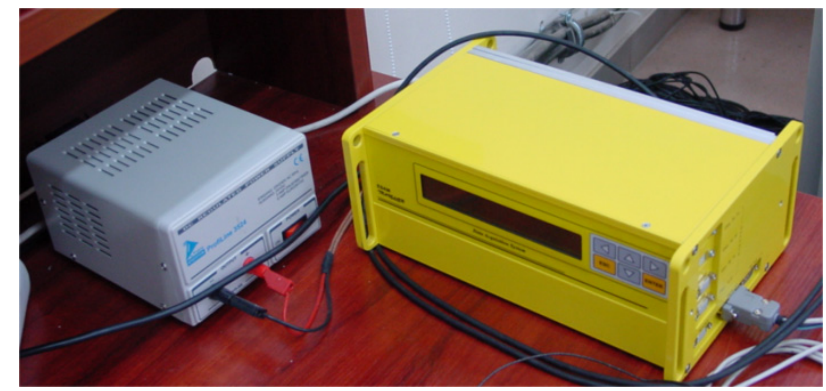

Fig. 5. Signal conditioner amplifier Traveller $\mathrm{CF}$

The strain gauges were installed on the specimens and controlled by the strain gauge bridge Traveller CF (Fig. 5), which recorded the progress of strains in time and synchronised them with the force measured by the Instron head. Sampling frequency was also equal to $20 \mathrm{~Hz}$. 

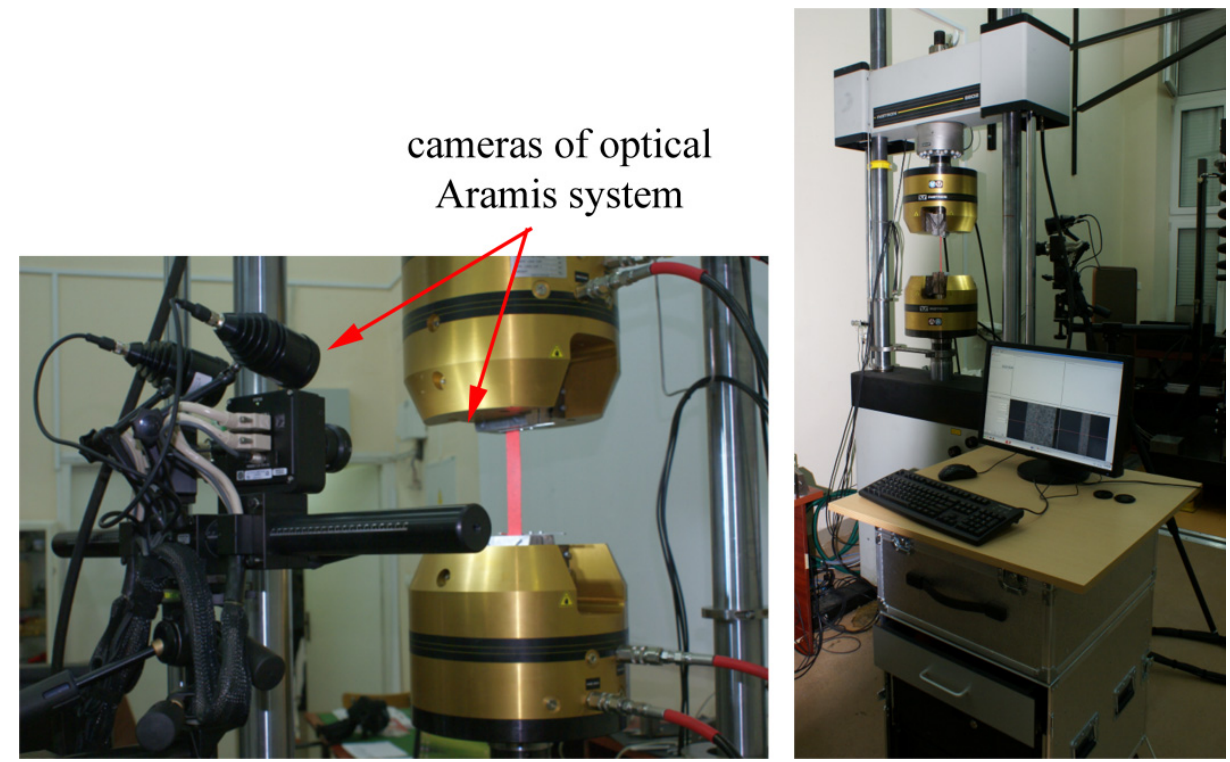

Fig. 6. Cameras of optical deformation measuring system Aramis installed in front of the specimen placed on the testing machine and the computer used to record and evaluate results

The strain field was detected with the usage of the Aramis system presented in Fig. 6.

Aramis is an optical system for the measurement of 3D deformations and strains in complex materials and structures during loading. This tool is a non-contact strain measuring testing device using 3D image correlation methods (digital image correlation, DIC).

The object is observed by two 3D high-resolution digital CCD cameras (2358x1728 pixels). Deformation of the structure during tensile loading is recorded by the cameras and evaluated using digital image processing. Owing to a special preparation procedure applied to a specimen's surface, the system can split images into rectangular areas called facets (size of $15 \times 15$ pixels was used in this case), which can be correlated with the corresponding areas on the other frames. The results in the 3D-coordinates are: $3 \mathrm{D}$ displacements, the surface strain and the complete strain tensor.

The system was calibrated with a $90 \times 74 \mathrm{~mm}$ calibrating plate. The $50 \mathrm{~mm}$ lenses were mounted. Aramis recorded 20 pictures per second so that a sampling rate was equal to one set in the Instron.

Based on the recorded pictures, strain fields of technical, logarithmic and Green strains can be automatically computed (locally in each facet) by the system [8].

The technical (engineering) strains are calculated with the following formula:

$$
\left\{\begin{array}{l}
\varepsilon=\frac{a}{a_{0}}-1=\frac{\Delta a}{a_{0}} \\
\sigma=\frac{P}{S_{0}}
\end{array}\right.
$$

where $a_{0}$ is the initial distance between the centres of two neighbouring square $3 \times 3$ facets (or the initial base length), $\Delta a$ is a distance/length increment, $P$ is the force recorded/measured by the Instron head, $S_{0}$ - the initial specimen cross section.

The strains are calculated using the gauge lengths set at the initial stage of the specimen load. On each specimen evaluated with Aramis system, three axial gauge lengths and two crosswise ones were set as follows: 
- $30 \mathrm{~mm}$ long axial gauge, placed symmetrically on the observed surface of the specimen (marked dX30);

- $5 \mathrm{~mm}$ long axial gauge, placed symmetrically on the observed surface of the specimen (marked dX5);

- $5 \mathrm{~mm}$ long axial gauge, placed symmetrically in the centre of the failure crack (marked $\mathrm{dX} 5 \mathrm{C})$;

- $8 \mathrm{~mm}$ long transversal gauge, placed symmetrically on the observed surface of the specimen (marked dY8);

- $8 \mathrm{~mm}$ long transversal gauge, placed symmetrically in the centre of the failure crack (marked dY8C).

The locations of gauge lengths on the analysed part of the specimen surface prepared for Aramis computing are shown in Figure 8. The initial values of the whole set of gauge lengths $\mathrm{dX} 30, \mathrm{dX} 5, \mathrm{dX} 5 \mathrm{C}, \mathrm{dY} 8$ and $\mathrm{dY} 8 \mathrm{C}$ for each evaluated specimen are presented in Table 2.
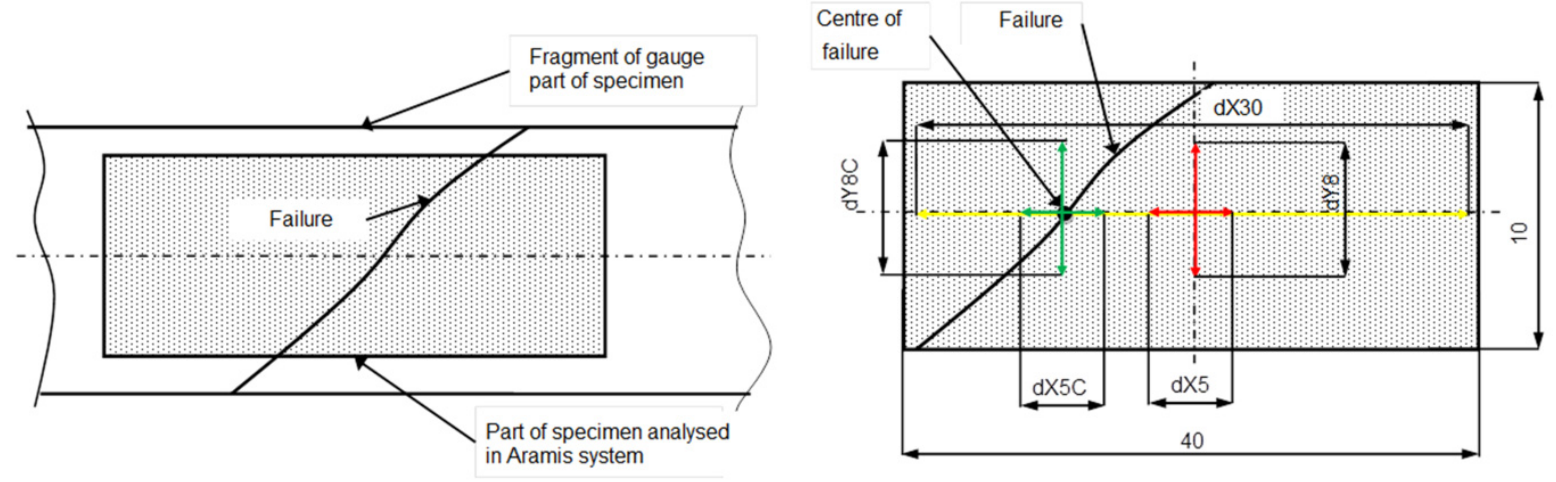

Fig. 7. Location of gauge lengths on the visible part of the specimen

Table 2. Actual initial values of gauge lengths for specimens analysed in Aramis system

\begin{tabular}{|l|l|l|l|l|l|l|}
\hline No. & Description & $\mathrm{dX} 30$ & $\mathrm{dX} 5$ & $\mathrm{dY} 8$ & $\mathrm{dX5C}$ & $\mathrm{dY}$ 8C \\
\hline 1 & BPw2 & 30,052 & 5,126 & 8,132 & 5,123 & 8,133 \\
\hline 2 & BPp1T & 30,138 & 5,062 & 8,101 & 5,070 & 8,107 \\
\hline 3 & ZPw2T & 30,140 & 5,067 & 8,106 & 5,057 & 8,103 \\
\hline 4 & ZPp1 & 30,037 & 5,130 & 8,134 & 5,133 & 8,138 \\
\hline
\end{tabular}

The Aramis system is equipped with an option to evaluate a map of thickness reduction. The data were used to compute the average thickness reduction along the gauge lengths $\mathrm{dX} 30$ and dY8C.

The following notation of the optical measurement data was adopted ( $x$ - longitudinal, $y$ - transverse, $z$ - thickness direction):

$\varepsilon_{x}, \varepsilon_{y}, \varepsilon_{z}$ - averaged strains (for the global gauge base $\mathrm{dX} 30$ and $\mathrm{dY} 8$ )

$\varepsilon_{x C}, \varepsilon_{y C}, \varepsilon_{z C}-$ strains for the local base in the centre of the failure crack (dX5C and dY8C)

$\varepsilon_{x \max }, \varepsilon_{y \max }, \varepsilon_{z \max }-$ strain at failure

The logarithmic strains and true stress in the plastic range (before the neck formation) was obtained using a well-known relationship $[1,2]$ :

$$
\left\{\begin{array}{l}
\varepsilon_{r z}=\ln \left(1+\varepsilon_{x}\right) \\
\sigma_{r z}=\sigma \cdot\left(1+\varepsilon_{x}\right)
\end{array}\right.
$$


In the elasto-plastic range to failure the following formulas were applied:

$$
\begin{aligned}
& \left\{\begin{array}{l}
a=a_{0}\left(1+\varepsilon_{x C}\right) \\
S=S_{0}\left(1+\varepsilon_{y C}\right) \cdot\left(1+\varepsilon_{z C}\right)
\end{array}\right. \\
& \left\{\begin{array}{l}
\varepsilon_{r z}=\ln \left(1+\varepsilon_{x C}\right) \approx-\ln \left(\left(1+\varepsilon_{y C}\right) \cdot\left(1+\varepsilon_{z C}\right)\right) \\
\sigma_{r z}=\frac{P}{S}=\frac{\sigma}{\left(1+\varepsilon_{y C}\right) \cdot\left(1+\varepsilon_{z C}\right)}
\end{array}\right. \\
& \left\{\begin{array}{l}
\varepsilon_{n}=\ln \left(1+\varepsilon_{x \max }\right) \approx-\ln \left(\left(1+\varepsilon_{y \text { max }}\right) \cdot\left(1+\varepsilon_{z \text { max }}\right)\right) \\
\sigma_{n}=\frac{\sigma}{\left(1+\varepsilon_{y \text { max }}\right) \cdot\left(1+\varepsilon_{z \text { max }}\right)}
\end{array}\right.
\end{aligned}
$$

\subsection{Tests results}

Specimens cross section $\mathrm{S}_{0}$, Young modulus $\mathrm{E}$, Poisson constant $v$, yield stress $\mathrm{R}_{02}$, ultimate stress $R_{m}$, and strain at failure $\varepsilon_{\mathrm{f}}$ for four types of specimen are presented in Table 3. Stress-stain graphs are compared in Fig. 8. The influence of a cladding surface (thickness $60 \mu \mathrm{m}$ ) is visible.

Table 3. Material properties

\begin{tabular}{|l|l|l|l|l|l|l|}
\hline description & \multicolumn{1}{c|}{$\mathrm{S}_{0}$} & \multicolumn{1}{c|}{$\mathrm{E}$} & \multicolumn{1}{c|}{$\mathrm{R}_{02}$} & \multicolumn{1}{c|}{$\mathrm{R}_{\mathrm{m}}$} & $\varepsilon_{\mathrm{f}}$ \\
\hline & {$\left[\mathrm{mm}^{2}\right]$} & {$[\mathrm{GPa}]$} & & {$[\mathrm{MPa}]$} & {$[\mathrm{MPa}]$} & \\
\hline $\mathrm{BPw}$ & 15,125 & 69,5 & 0,320 & 350,5 & 484,0 & 0,199 \\
\hline $\mathrm{BPp}$ & 15,125 & 69,3 & 0,311 & 318,5 & 469,0 & 0,221 \\
\hline $\mathrm{ZPw}$ & 15 & 68,1 & 0,318 & 340,1 & 454,2 & 0,226 \\
\hline $\mathrm{ZPp}$ & 15 & 67,2 & 0,314 & 329 & 450,1 & 0,240 \\
\hline
\end{tabular}

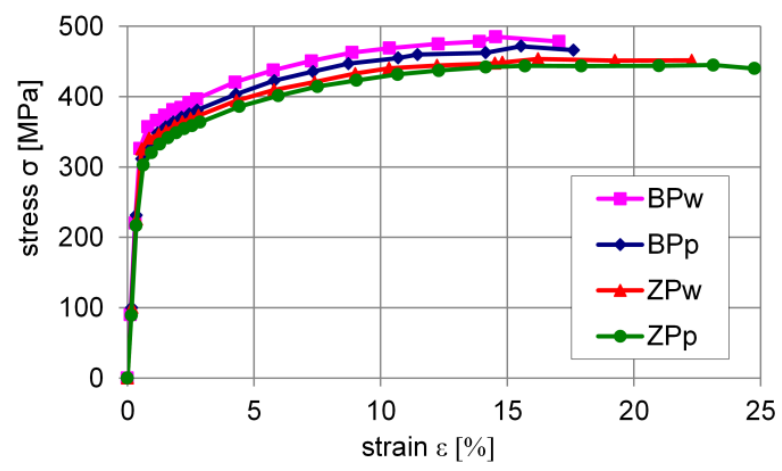

Fig. 8. Engineering stress-strain curves

Selected strain fields (for BPw2 specimen) are presented in Fig. 9 (scale from 0\% to 38\%).

Engineering (1) and true strain-stress curves $(2,4,5)$ are compared in Fig. 11. The method of least squares was used to determine the parameters of the power model $\sigma=K \cdot \varepsilon^{n}$ on the basis of the true stress-strain data (Fig. 12). The comparison of the true stress-strain data, the power model and stress-strain at failure is presented in Fig. 13. 


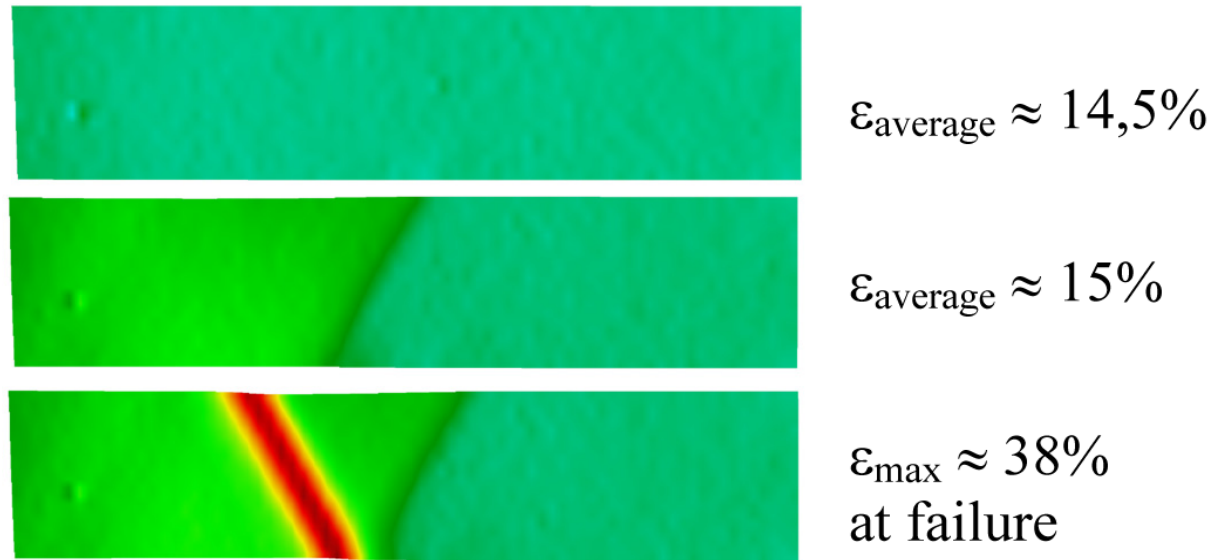

Fig. 9. Strain fields - longitudinal component

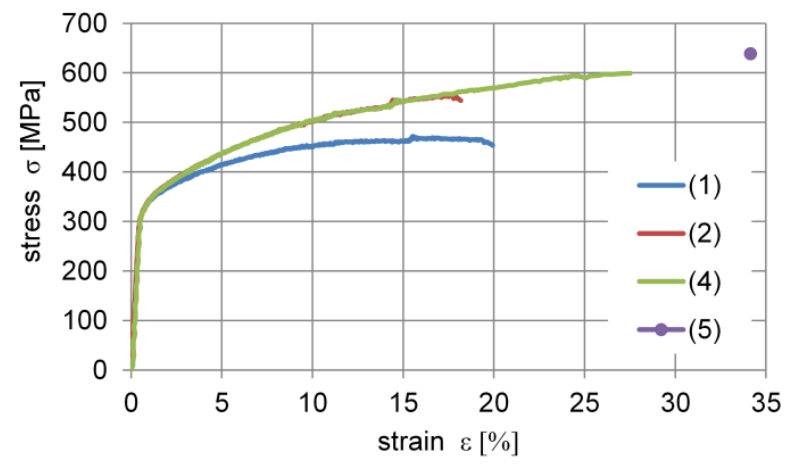

Fig. 10. Stress-strain curves: technical (1), true (2) and (4), at failure (5)

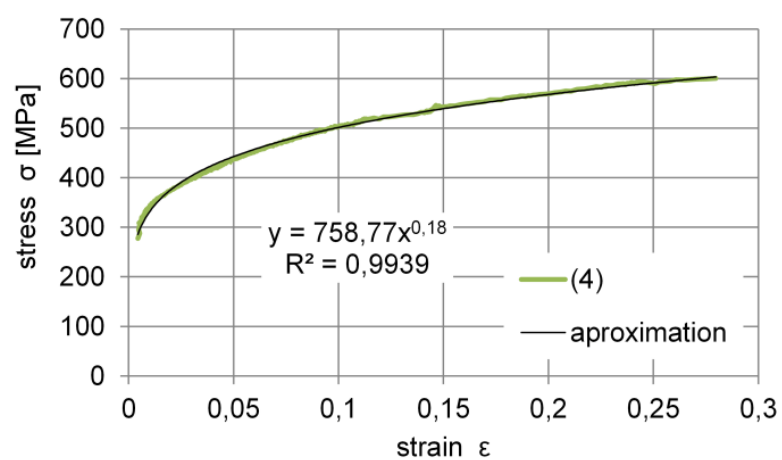

Fig. 11. Parameter of the power model $\sigma=K \cdot \varepsilon^{n}$

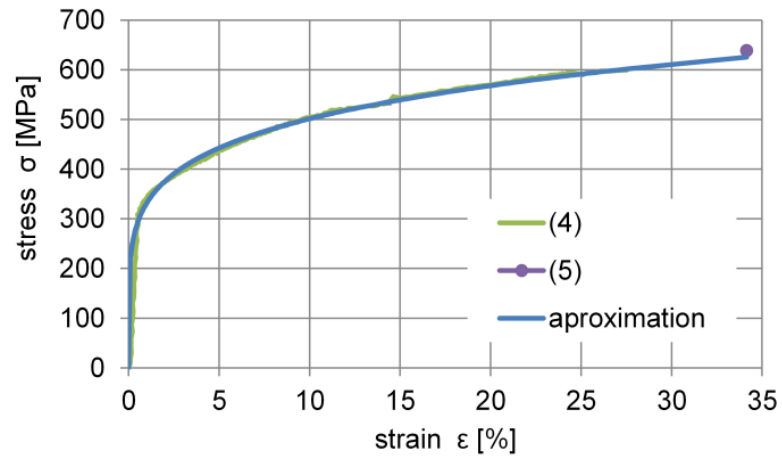

Fig. 12. Verification of the local gauge data and the failure point 


\subsection{Material structure analysis}

Analysis of voids nucleation in aluminum alloy after static testing of a sheet with a hole was performed using SEM (scanning electron microscope). Fractographic analysis was carried out at the Department of Advanced Materials and Technology.

The static test was performed for the aluminum alloy (2024T3) specimen with a hole. The tensile force and strains at three points were measured during the test. The location of the measurement points on the specimen is presented in Fig. 13 (no. 1 is placed in a full cross section, no. 2 and 3 in the hole cross section).
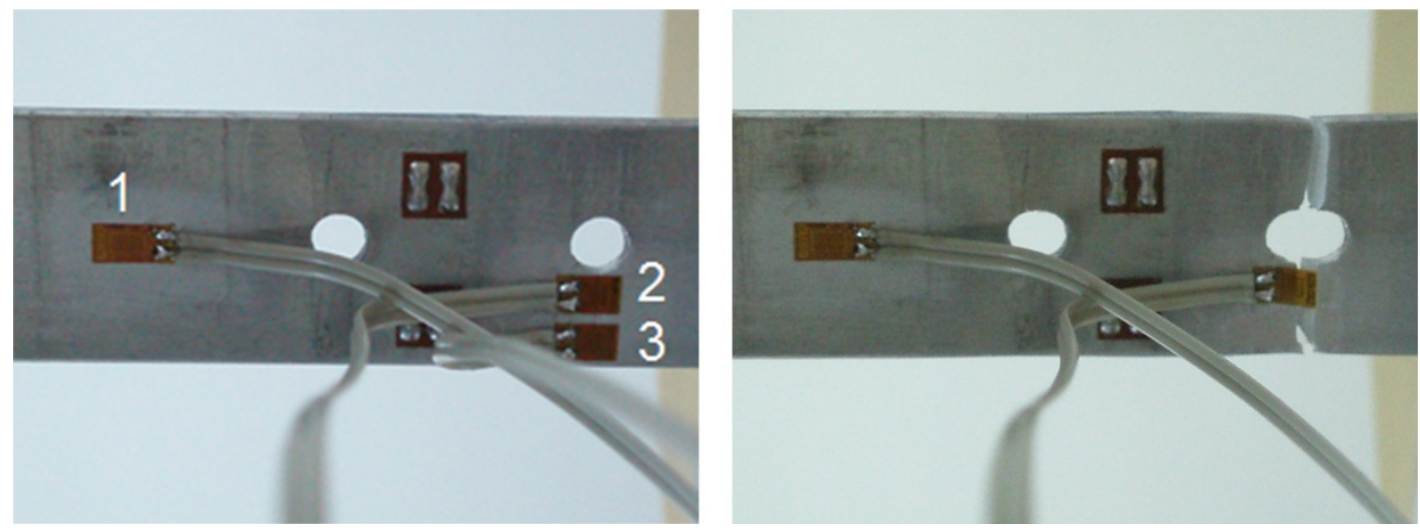

Fig. 13. The measurement points location

The maximum strain value at point no. 1 was about $0.4 \%$ while in the hole cross section it achieved $0.58 \%$ and $1.5 \%$ at point no. 3 and no. 2 respectively (Fig. 14).

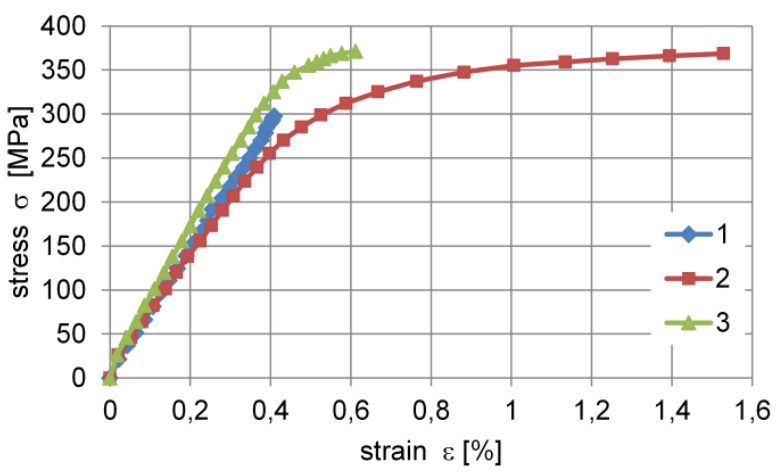

Fig. 14. Stress-strain curves during tensile loading for three selected points

After the test, the SEM analysis of the material structure in the elastic and high plastically deformed area was carried out. In the elastic area (around point no. 1) a regular crystal structure and frequent inclusions (i.e. iron inclusion phases) were observed (Fig. 15). During tensile loading crystals are also stretched. Then a micro crack may be initiated at the inclusion particles and then voids grow around it (Fig. 16). The material structure around the inclusions and micro-cracks are presented in the photos. 

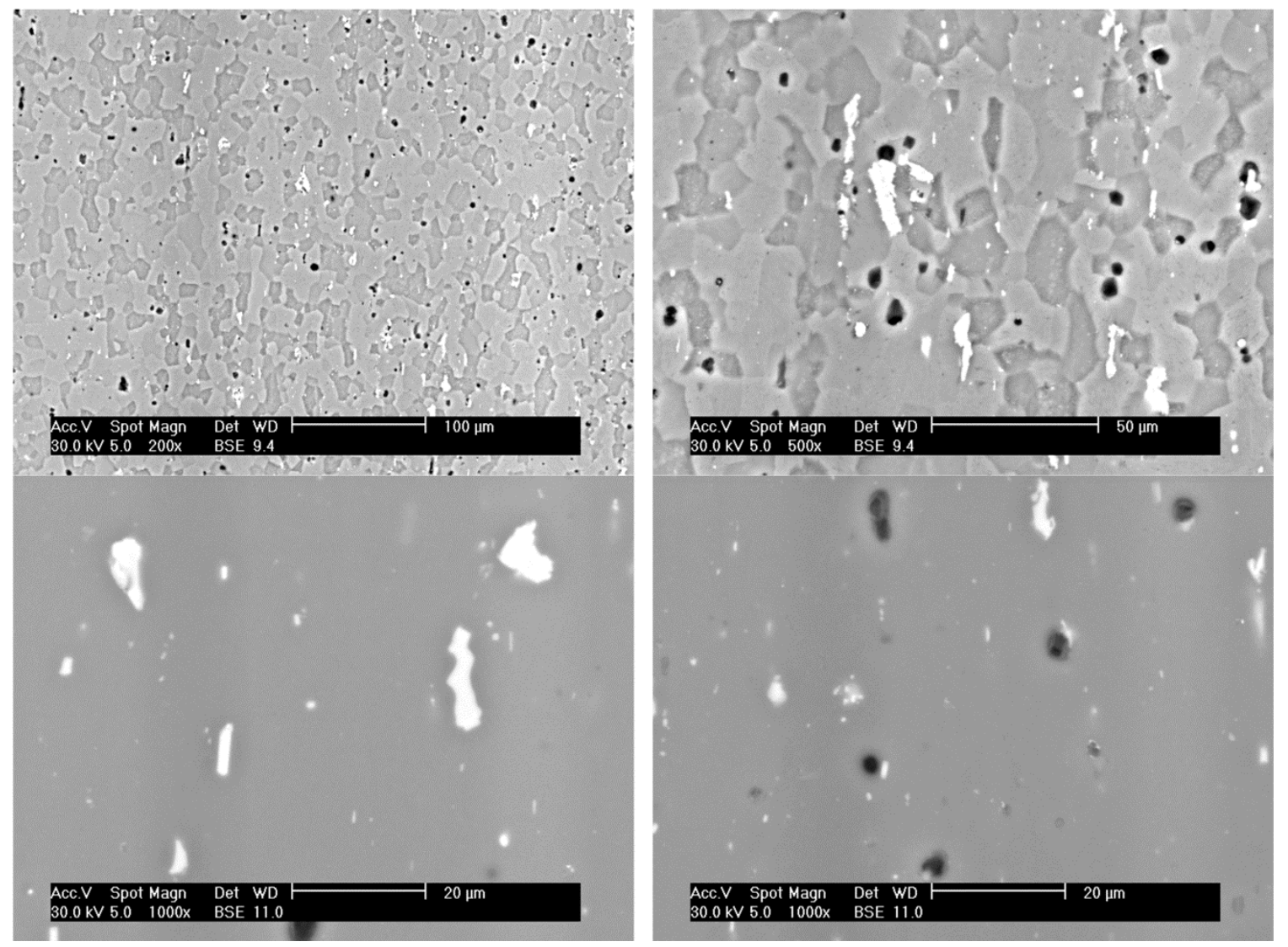

Fig. 15. Material structure (area 1)
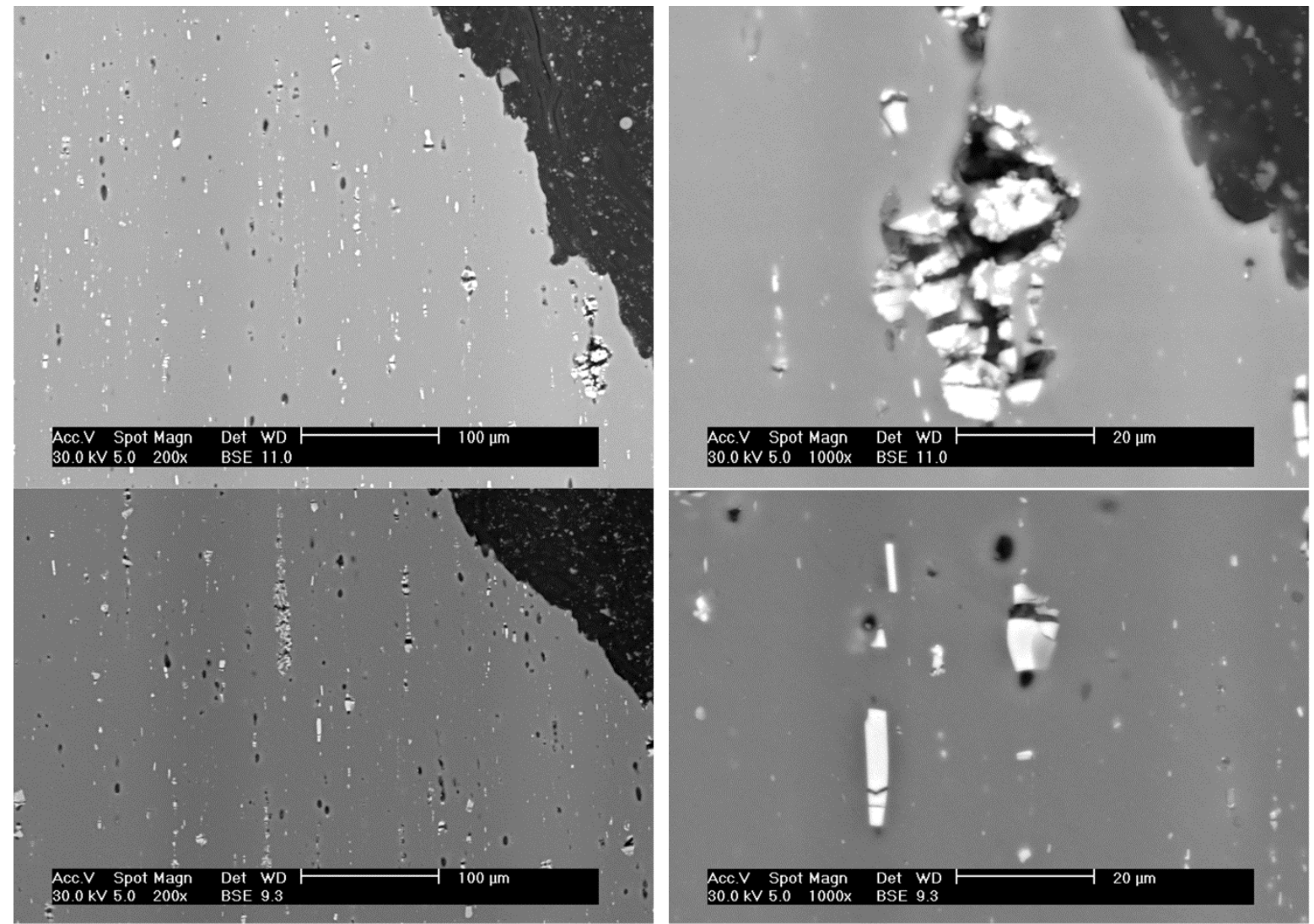

Fig. 16. Material structure (highly deformed area 2) 
In ductile materials (such as aluminium alloy) subjected to tensile loading conditions, voids may form, which grow and then coalesce leading to crack formation and, potentially, a failure. Experimental studies showed that these processes are strongly influenced by hydrostatic stress. Gurson studied microscopic voids in materials and derived a set of modified constitutive equations for elasto-plastic materials [3]. Tvergaard and Needleman [4, 5] modified this model with respect to the behaviour of small void volume fractions and void coalescence.

\section{NUMERICAL ANALYSIS}

\subsection{Material models}

The sheets were made of $2024 \mathrm{~T} 3$ aluminum alloy. Calculations were performed for the elastoplastic material (Young's modulus of elasticity E is equal to $68000 \mathrm{MPa}$, Poisson ratio is 0.3 and yield stress is $350 \mathrm{MPa}$ ). The von Misses yield criterion for the multi-axial state was assumed [7]:

$$
\sigma_{\text {equivalent }}=R_{e}
$$

where $R_{e}$ is yield stress.

In the modified Gurson model, the amount of damage is indicated with a scalar parameter called the void volume fraction $f$. The yield criterion for the macroscopic assembly of voids is given by $[4,5]$ :

$$
\begin{aligned}
& F=\left(\frac{\sigma_{\text {equivalent }}}{R_{e}}\right)^{2}+2 q_{1} f^{*} \cosh \left(\frac{q_{2} \sigma_{k k}}{2 R_{e}}\right)-\left[1+\left(q_{1} f^{*}\right)^{2}\right]=0 \\
& f^{*}=\left\{\begin{array}{lll}
f & \text { if } & f \leq f_{c}, \\
f_{c}+\left(\frac{1 / q_{1}-f_{c}}{f_{F}-f_{c}}\right)\left(f-f_{c}\right) & \text { if } & f>f_{c}
\end{array}\right.
\end{aligned}
$$

where: $q_{1}, q_{2}$ - constants introduced by Tvergaard to improve the Gurson model at small values of the void volume fraction, $f$-void volume fraction, $f_{c}$ - critical void volume fraction, $f_{F}$ - void volume at failure.

The void volume fraction changes (3) due to the growth $\dot{f}_{\text {growth }}$ of existing voids and the nucleation $\dot{f}_{\text {nucleation }}$ of new voids:

$$
\begin{gathered}
\dot{f}=\dot{f}_{\text {growth }}+\dot{f}_{\text {nucleation }} \\
\dot{f}_{\text {growth }}=(1-f) \dot{\varepsilon}_{k k}^{p} \\
\dot{f}_{\text {nucleation }}=\frac{f_{N}}{S \sqrt{2 \pi}} \exp \left(-\frac{1}{2}\left(\frac{\varepsilon_{m}^{p}-\varepsilon_{n}}{S}\right)^{2}\right) \dot{\varepsilon}_{m}^{p}
\end{gathered}
$$

where $\varepsilon_{i j}^{p}$-plastic strain tensor, $f_{N}$ - volume fraction of void forming particles, $\varepsilon_{n}$ - mean strain for void nucleation, $S$ - standard deviation for void nucleation. 
Parameters of Gurson's material model were chosen according to literature data $[4,5]$ as well as numerical and experimental data obtained for the sheet with an open hole. Consequently, the following values were assumed (Table 4). In this case cross section necking at rupture obtained from the numerical analysis was about $16 \%$ and it was in good agreement with the experimental results.

Table 4. Parameters of the material model

\begin{tabular}{|l|l|l|l|l|l|l|l|}
\hline$q 1$ & $q 2$ & $f$ & $f_{c}$ & $f_{F}$ & $\varepsilon_{n}$ & $S$ & $f_{N}$ \\
\hline 1.5 & 1 & $5.7 \mathrm{E}-4$ & 0.15 & 0.25 & 0.2 & 0.07 & 0.04 \\
\hline
\end{tabular}

\subsection{Numerical results}

Analysis was performed for a square sample (sheet side $10.5 \mathrm{~mm}$ wide and $1.2 \mathrm{~mm}$ thick) shown in Fig. 18a. The FE simulations were carried out using the MSC Marc code. The FE model consisted of eight-node, isoparametric, three-dimensional brick elements (type Hex8) with a trilinear interpolation function [7]. Kinematic load (displacement dx equal to $1 \mathrm{~mm}$ ) was applied. Boundary conditions are shown in Fig. 18b. The classical updated Lagrange formulation (with a large strain plasticity option) for elastic-plastic materials was used due to large geometrical and material non-linearities.
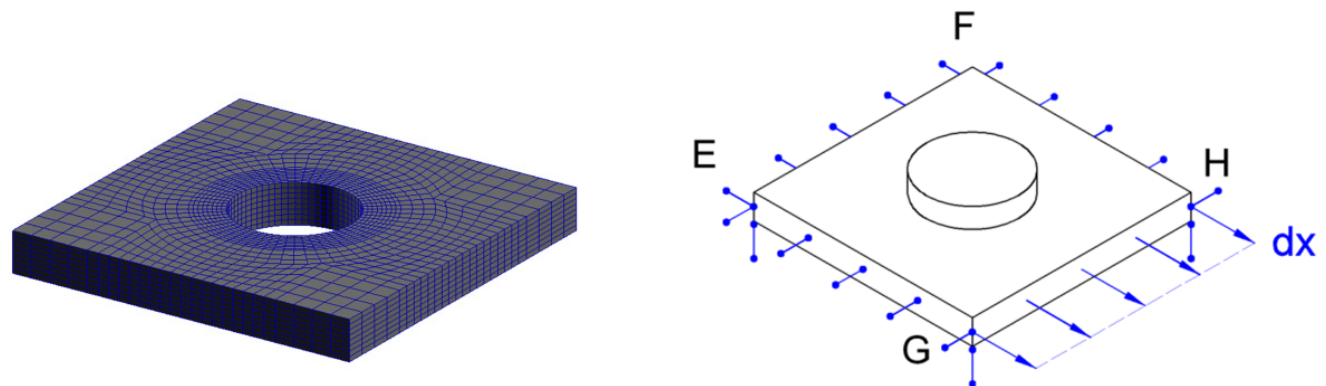

Fig. 17. a) square sample - the FE model b) boundary conditions

load $22 \% \mathrm{dx}$

The elasto-plastic model

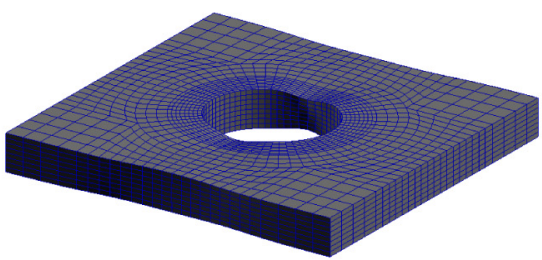

$34 \% \mathrm{dx}$

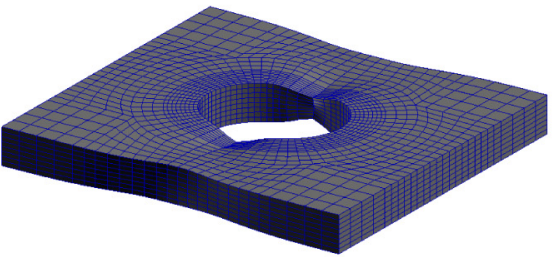

$100 \% \mathrm{dx}$

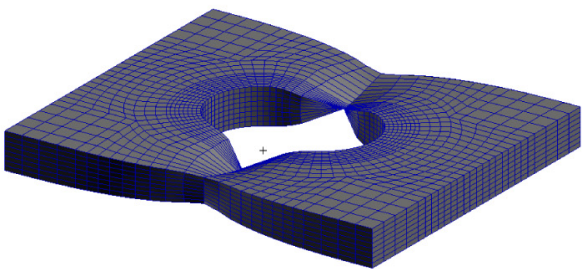

Gurson's model
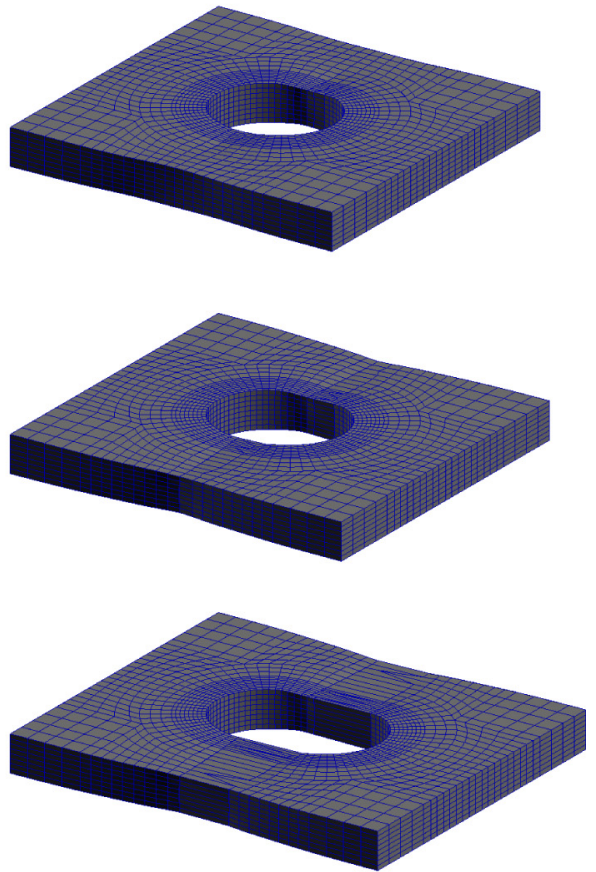

Fig. 18. Sample deformation 
The comparison of sample deformations and strain fields during tensile loading for two material models is presented in Fig. 19 and 20. For the Gurson material model, the sheet transmitted load as long as the displacement reached $34 \% \mathrm{dx}$ (then separation occurred) whereas in the case of the elasto-plastic material model the load was transferred all the time and the sheet cross section decreased to zero (which is a non-physical behaviour).

load

a) the elasto-plastic model

b) Gurson's model

$4 \% \mathrm{dx}$
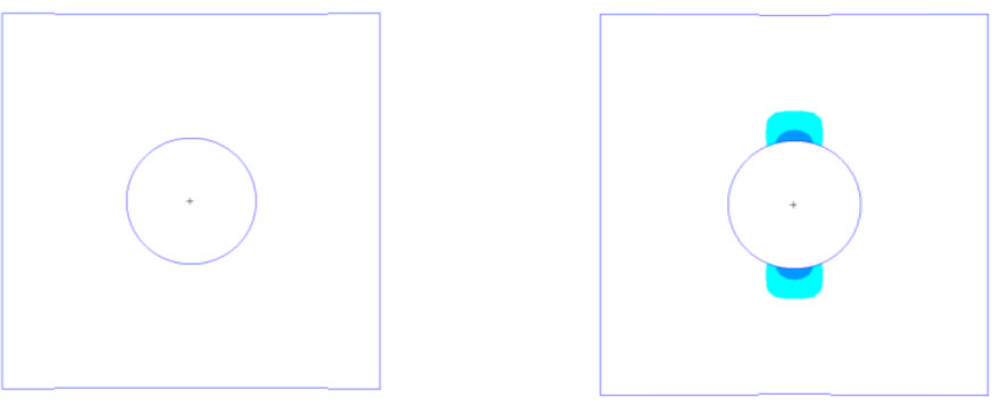

$22 \% \mathrm{dx}$
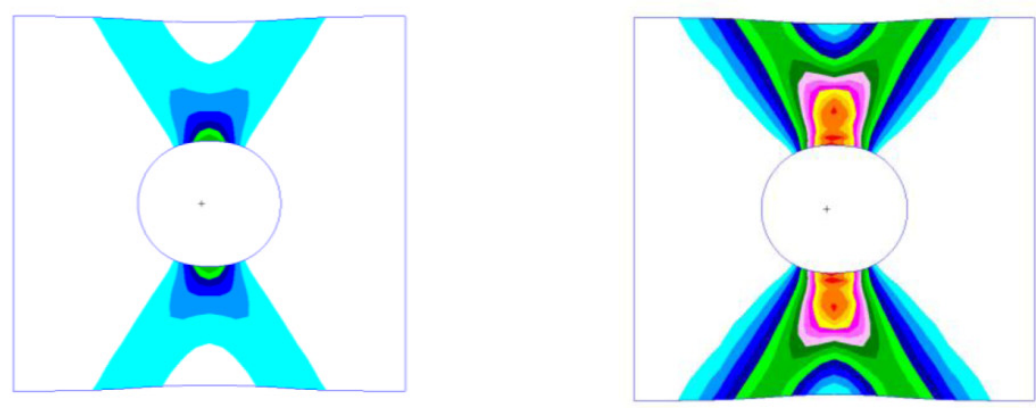

$34 \% \mathrm{dx}$
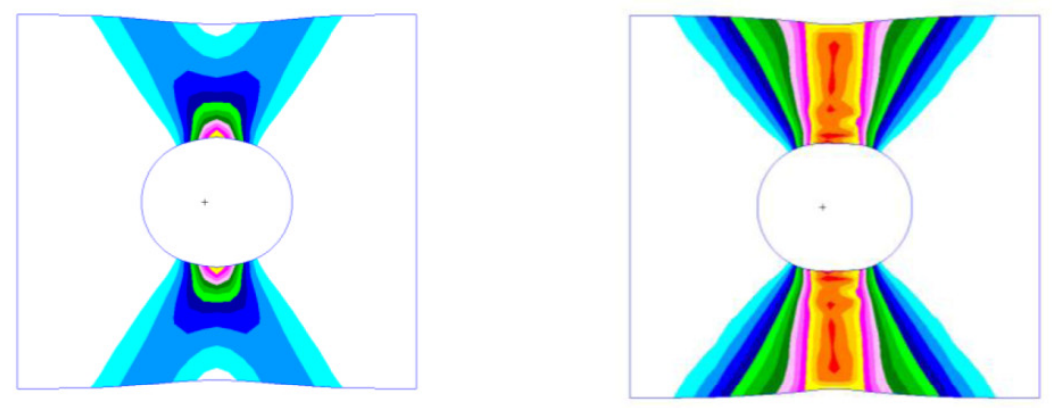

$100 \% \mathrm{dx}$
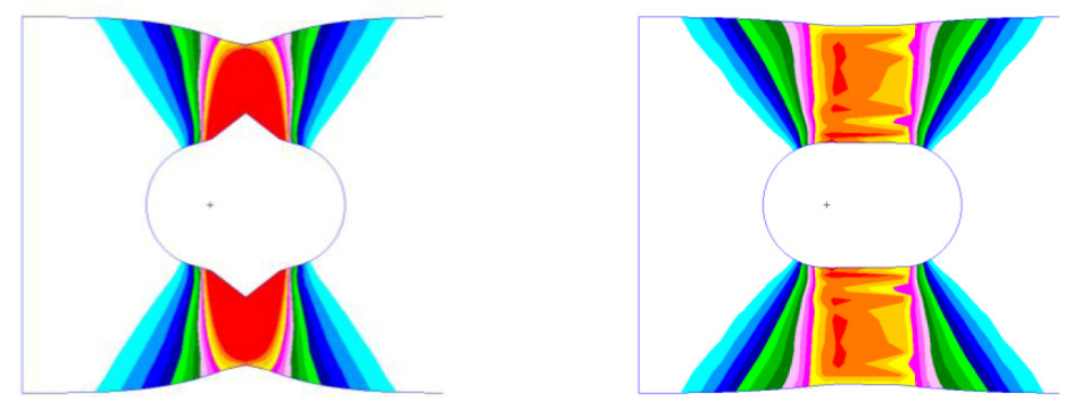

a) 0

\begin{tabular}{|l|l|llllllllll|l|l|}
\hline & & & & & & & & & & & & $\%$ \\
\hline 0 & 6 & 12 & 18 & 24 & 30 & 36 & 42 & 48 & 55 & 61 & 67 & 73 \\
0 & 1.5 & 3.0 & 4.5 & 6.0 & 7.5 & 9.0 & 10.5 & 12.0 & 13.5 & 15.0 & 16.5 & 18.0
\end{tabular}

Fig. 19. Strain fields 
load The elasto-plastic model

$10 \% \mathrm{dx}$

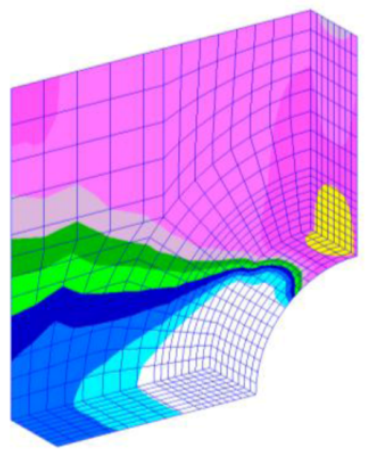

$22 \% \mathrm{dx}$

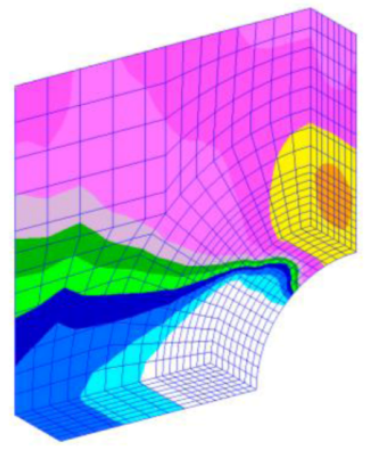

$34 \% \mathrm{dx}$

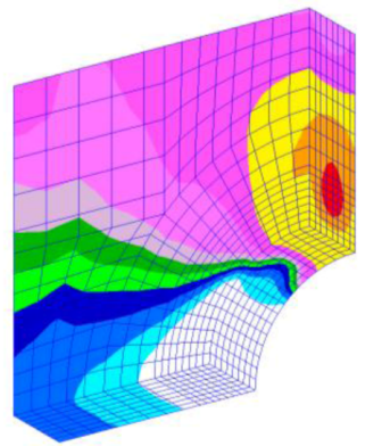

Gurson's model
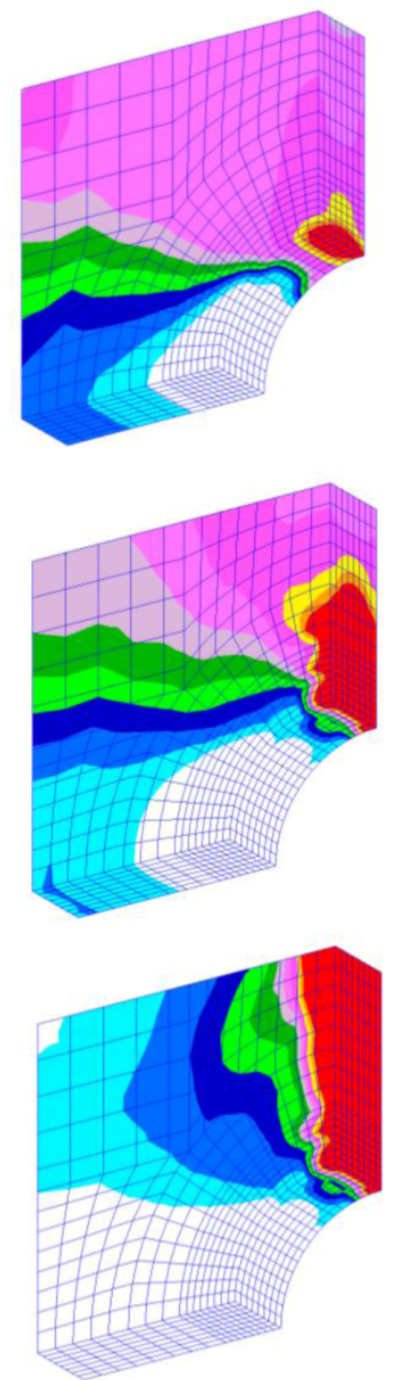

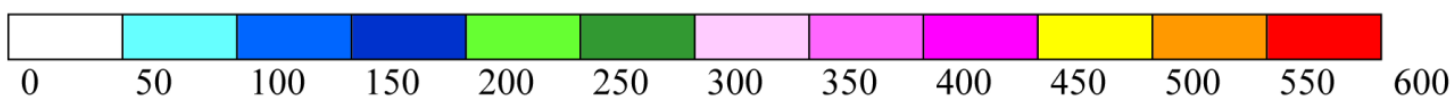

Fig. 20. Principal stress fields

Analysis of the principal stress fields for Gurson's model (Fig. 21) also allows recognition of gradual material separation during sample loading.

The application of Gurson's material model in the simulation of a riveted joint was presented in the paper [6]. The influence of residual stresses (after riveting) on the sheet rupture in the static tensile condition is not very important. Compressive residual stress fields have a significant influence on fatigue behaviour of riveted joints.

\section{CONCLUSIONS}

The aim of the investigation was to evaluate the material properties of $2024 \mathrm{~T} 3$ aluminium alloy subjected to various treatments (i.e. cladding, rolling direction). The strength of cladded sheets is about $7 \%$ lower than that of the bare ones (it is strictly joint with cladding layer thickness). The influence of the rolling direction on yield and limit stresses is about 5-6\% in the case of bare sheets (specimens loaded in the rolling direction are stronger), whereas for cladded material the difference is lower than $2 \%$. 
The strain fields were detected with the Aramis system. It is an optical system for non-contact measurement of 3D deformations and strains in materials and structures during loading. The area of maximum/high plastic deformations, which was placed in the angle of $60^{\circ}$ to the specimen axis, moved along the specimen and material separation occurred in this area.

The analysis of 2024T3 alloy structure is presented in the paper. In the elastic area, the regular crystals and frequent inclusions (i.e. iron inclusion phases) were observed. During the tensile loading the crystals were also stretched. Then a micro crack may be initiated at the inclusion particles and then voids grow around it.

The effect of a material model on the results of the numerical simulation of a tensile loaded sample with a hole is presented. The application of Gurson's material model (with void nucleation) allows for determination of the sheet rupture as the moment when constraint force decreases to zero (material separation occurs), whereas for standard elasto-plastic material the criterion of failure can be defined as either strain (plastic strain) or stress dependent. Gradual material separation during loading can be observed using strain fields as well as principal stress fields.

Additionally, necking of the sheet cross section can be correctly determined only if Gurson's model is applied. Otherwise (for standard elasto-plastic material), the cross section decreases to zero.

\section{REFERENCES}

[1] Dyląg Z., Jakubowicz A., Orłoś Z. (1996). Wytrzymałość Materiałów. WNT, Warszawa.

[2] Kocańda S. (1985). Zmęczeniowe pękanie metali, WNT, Warszawa. Wydanie III rozszerzone.

[3] Gurson, A.L. (1977). Continuum theory of ductile rupture by void nucleation and growth. Part I - Yield criteria and flow rules for porous ductile media, Engineering Materials and Technology, 99, pp. 2-15.

[4] Tvergaard V. Influence of voids on shear band instabilities under plane strain conditions. Int J Fract (1981), 17: 389-407.

[5] Tvergaard V. On localization in ductile materials containing spherical voids. Int J Fract (1982), 18: 237-52.

[6] Szymczyk E., Sławiński G. (2010). Influence of material model on tensile loaded joint, Solid State Phenomena, 165(2010), pp. 394-399.

[7] MSC Marc, Theory and User Information, MSC Corp. 2010.

[8] Aramis, Documentation 2010.

[9] ASTM A 370-03a, Standard Test Method for Tension Testing of Metallic Materials, 2003. 